patients with Hodgkin's disease can be cured without chemotherapy. This contribution to the debate on the provision of cancer services would be better forgotten.

Bristol Radiotherapy and Oncology Centre,

G J G REES Bristol BS2 8ED

\section{Data Protection Act}

SIR,-While the introduction of the Data Protection Act raises general questions about access to medical records, we would raise a note of caution over Professor Frederick V Flynn's statement that each doctor should consider what information he ought to record in computer files (7 November, p 1160). The Data Protection Act is for the safety of individuals, and its introduction is clearly in line with society's move towards increased "glasnost." If data are not going to be recorded on computer because individuals have the right of access we suggest that this runs contrary to the spirit of the act and is likely to result in the very rapid extension of the act to cover manual records.

It is also worth noting that the modified access to health records allows the health care professionals concerned to withhold information which, as Professor Flynn stated, "is likely to cause serious harm to the physical or mental health of the patien or another person." This clause in the modification to access is clearly open to a wide range of interpretation and the registrar suggests that it should be applied only in rare instances. It is not therefore an "escape clause." We would like to correct one point of fact in the article: in cases where the health professional does feel that data should be withheld he or she is not obliged to tell the person applying that anything has not been disclosed; nor is there any requirement to indicate why.

This part of the act is explained more fully in health circular (87)14 (annex B (1)), which states, "The fact that information has been withheld could be as harmful to data subjects as the information itself." It goes on to add that a standard disclaimer about the information released should be used. The Data Protection Act will un doubtedly pose extra work for medical staff, but, as Professor Flynn states, it may be reduced by the fostering of good doctor-patient relationships.

P GOSSMAN

J R WILKINSON

South Cumbria Health Authority,

Barrow in Furness,

Cumbria LA13 9JU

1 Department of Health and Social Security. Data Protection Ac 1984: modified access to personal health information. London: Department of Health and Social Security, 1987. (HC(87)14.)

\section{All change for research}

SIR,-Dr Richard Smith indicated that "selectivity" in research "raised a storm of protest, particularly because it was not made clear how the judgments were made and because there was no appeal" (7 November, p 1177). On 30 September 1987 the senate of the University of Surrey decided to close down the Unity Laboratory of Applied Neurobiology, allegedly on the grounds of cost. On 5 November the finance and general purposes committee was told that "selectivity" was a further ground for the decision. I presented papers showing that the Unity Laboratory cost University Grants Committee funds $£ 15500$ per year per member of the academic staff, compared with $£ 20000$ to $\$ 50000$ per year per member of the biological departments, during 1985-6 and 1986-7.

When "selectivity" was given as the reason for closure, however, the questions raised were: Who selected the Unity Laboratory for closure? Were they peers? Had any of those who selected it read a substantial number or, indeed, any of the publications from the laboratory? Why was the director neither asked to produce any information about the laboratory for the assessors nor invited to submit publications before the decision, nor even told that there was to be such an assessment? Since it was carried out by university staff it could have been done only by senior members of the three biology departments of the university. The fact that none of them were neurobiologists indicates that they had rather poor credentials to assess the quality of neurobiological research. The allocations to these departments for 1987-8 were cut by $5 \%$ compared with the Unity Laboratory which was not assessed by the University Grants Committee) being cut to zero. Since 1969,71 substantive publications, including three books, have resulted from the work of the laboratory.

The real dangers of "selectivity" are that it discourages original thinking, theoretical work, individual or small team research, research not naturally attracting external funds, and questioning and innovative research, without which important advances cannot be made.

\section{HaRold Hillman}

Unity Laboratory of Applied Neurobiology,

University of Surrey,

Guildford, Surrey GU2 5XH

\section{Doctors as general managers}

SIR,-Mr Russell Hopkins's article (21 November, p 1360) prompts me to say how much we medical general managers appreciate the initiative of the BMA in enabling us to come together on an informal basis and its decision to look favourably on more formal arrangements to represent our interests. Mr Hopkins writes mainly from the standpoint of clinicians in general management. Nevertheless, at the meeting on 20 October which I attended, and which he chaired, many of those present were from the specialty of community medicine. Our community medicine training does, of course, include the acquisition of management skills, which are of considerable help if we decide to transfer to general management. I heartily endorse all that Mr Hopkins says about the need for clear direction and agreed objectives in management, as well as the essential support from the NHS Management Board for the principles of general management, which is at present so conspicuously lacking.

Medical general managers are a hybrid group, but we have the potential to exert a unique influence on the development of policies in the NHS, which will benefit both the individual patient and the local population. If doctors, from whatever specialty, are to be encouraged to undertake general management there must be a forum in which they can discuss common problems and I strongly support the formation of a special group within the BMA to represent their interests. Neither the NHS nor the medical profession can afford to waste the skill that is available.

\section{ENID C VINCENT}

Wandsworth Health Authority, St George's Hospital, London SW17 0QT

\section{How to run a clinical budget}

SIR,-Has Mr K A M Grant merely picked on an unfortunate example (31 October, p 1110) or is he really suggesting that, in future, money for the continuing education of doctors will come from the same budget as clinical care and be directly linked to it? We would then have the dilemma of whether to spend the money on patients or on ourselves. For example, if I wished to attend an important conference on breast cancer would I have to stop prescribing cytotoxic drugs to patients with the disease in order to pay the registration fee?

Further education for doctors is vital to maintain an up to date and efficient workforce, and for these reasons it should be encouraged and supported. If this example becomes reality doctors most concerned about giving their patients the best care possible while under economic restraint are likely to put themselves at the bottom of the list, and never attend another meeting unless they can afford their own expenses. Or do we turn to the drug companies but keep it quiet?

Bristol Radiotherapy and Oncology Centre

SALLY GoOdMaN Bristol

\section{Oral contraceptives and breast cancer}

SIR,-By courtesy of the editor of the British Fournal of Cancer and the authors concerned, the Committee on Safety of Medicines has been able to review the paper by McPherson and colleagues which is to appear under the title of "Early contraceptive use and breast cancer: results of another case-control study" in the November issue of the British fournal of Cancer.

The paper adds to the considerable body of knowledge which has now accumulated on this subject. At least eight substantial case-control studies in which the possible relation between oral contraceptive use and breast cancer was investigated have been published since 1980 . Most of these studies, including the largest of them-the American cancer and steroid hormone study -have provided no cause for concern. Some, however, have raised questions about a possible adverse effect of prolonged oral contraceptive use early in life.

The forthcoming publication by McPherson and colleagues suggests that there may be a two and a half fold increase in the risk of breast cancer in women up to 45 years of age who have had four or more years of oral contraceptive use before their first full term pregnancy. The authors point out that their data do not directly reflect the use of the modern low dose oral contraceptive pills. In addition, this study has found no association between oral contraceptive use after first full term pregnancy and breast cancer either in women under 45 years of age or in older women. The paper extends the previously reported results of these authors (published in December 1983), which were fully considered by the Committee on Safety of Medicines at the time of their appearance.

The Committee on Safety of Medicines has considered the additional results now being made available in the light of all the current evidence. It will continue to monitor the several studies which are still in progress on this subject but agrees with the view of McPherson and others that the newly reported findings do not indicate the need to change at this time the current advice regarding the use of the presently available oral contraceptive agents. Thus the committee remains of the view that women receiving oral contraceptives should be prescribed a product with the lowest suitable content of both oestrogen and progestogen.

Committee on Safety of Medicines,

A W ASSCHER

London SW8 SNQ 